\title{
QUEBRA DE DORMÊNCIA DO FAVÃO PARA O USO NA RECUPERAÇÃO DE ÁREAS DEGRADADAS EM MARABÁ-PA
}

\author{
Jayane Santos Nunes ${ }^{1}$; Clarissa Mendes Knoechelmann² ${ }^{2}$ Andréa Hentz de \\ Mello ${ }^{3}$; Raimundo Nonato do Espírito Santos ${ }^{4}$; Ana Valéria dos Reis Pinheiro ${ }^{4}$; Eliade Rocha \\ dos Santos. \\ ${ }^{1}$ Discente de Agronomia da Faculdade de Ciências Agrárias de Marabá, Universidade Federal do Pará, \\ jayzinhanunes@ hotmail.com \\ ${ }^{2}$ Professora Assistente I da Faculdade de Ciências Agrárias de Marabá (FCAM), Universidade Federal do Pará, \\ clarrissa@ufpa.br \\ ${ }^{3}$ Professora Adjunta II da Faculdade de Ciências Agrárias de Marabá, Universidade Federal do Pará, SINDCERV, \\ andreahentz@ufpa.com \\ ${ }^{4}$ Professores Adjuntos da Faculdade de Geologia da Universidade Federal do Pará.
}

\begin{abstract}
RESUMO: A recuperação de áreas degradadas torna-se uma alternativa para o meio ambiente e social. Em Marabá-PA áreas em que são realizadas atividades de extração de argila encontram-se degradadas.O favão (Parkia multijuga Beth) é uma leguminosa e é comum sua ocorrência na região Amazônica. O objetivo deste trabalho foi verificar o melhor método de quebra de dormência para o favão, observando a taxa de germinação. O delineamento experimental em casa de vegetação foi um fatorial no delineamento inteiramente casualizado (DIC), contendo uma espécie vegetal, um tipo de substrato, três métodos de quebra de dormência que consistiu em testemunha (sem quebra de dormência) (TR1), escarificação mecânica (TR2) e imersão das sementes em $\mathrm{H}_{2} \mathrm{SO}_{4}$, por 16 minutos (TR3), onde usou-se 40 repetições, totalizando 120 vasos $(1 \times 1 \times 3 \times 40)$. Para obter os dados da germinação foi usado regra de três simples usando o valor da quantidade de sementes germinada com a quantidade de sementes semeadas. Os dados foram analisadas e submetidas a testes de média e de variância de Tukey a 5\% de probabilidade, segundo metodologia descrita no software SISVAR.. O método de superação da dormência do favão mais eficiente foi a escarificação mecânica.
\end{abstract}

PALAVRAS-CHAVES: germinação, Parkia multijuga, reabilitação.

\section{BREAKING DORMANCY FAVÃO FOR USE OF THE RECOVERY OF DEGRADED AREAS IN MARABÁ-PA}

\begin{abstract}
The recovery of degraded areas becomes an alternative for the environment and society. Marabá-PA in areas where activities clay extraction is conducted is degradation. $\mathrm{O}$ bean (Parkia multijuga Beth) is a legume and is a common occurrence in the Amazon region. The aim of this study was to determine the best method of breaking dormancy for Fava, noting the rate germination. The experiment in the greenhouse was a factorial in completely randomized design (CRD), containing a plant species, a type of substrate, Three methods of breaking dormancy which consisted of a control (without breaking dormancy) (TR1), mechanical scarification (TR2) and Soaking in $\mathrm{H}_{2} \mathrm{SO}_{4}$ for 16 minutes (TR3), where it used to 40 repetitions, totaling 120 pots $(1 \times 1 \times 3 \times 40)$. For the germination data was used three simple rule using the value of the quantity of seeds germinated with the amount of seeds sown. The data were analyzed and subjected to the tests mean and variance of Tukey at $5 \%$ probability, using methods described in the software SISVAR. The method to overcome dormancy of bean was the most efficient chiseling.
\end{abstract}

KEY-WORDS: germination, Parkia multijuga, rehabilitation.

Agroecossistemas, v. 3, n. 1, p. 96-100, 2011 
Áreas degradadas são tipicamente caracterizadas por solos pobres, erodidos, com instabilidade hidrológica, produtividade reduzida, pouca diversidade biológica $\mathrm{e}$ alteração das características físicas e químicas (SANCHEZ, 2003). A atividade de extração de argila implica na retirada da vegetação natural e intensa movimentação de solo, gerando em alguns casos consideráveis buracos que contribuem para o distúrbio da área, além de promover com a retirada dos nutrientes, alta toxidez de metais no solo. A maioria das áreas em que são realizadas atividades de extração de argila em Marabá PA encontram-se degradadas, devido retirada da vegetação natural, o que facilita o processo de erosão. O solo apresenta-se erodido, com considerável quantidade de rejeito, prejudicando também a microbiota do solo que tem papel fundamental na ciclagem de nutrientes, e mananciais de água, como as margens do rio Itacaiúnas. A recuperação destas áreas degradadas torna-se uma alternativa importante para o meio ambiente e social, pois busca com estudos e ações amenizar impactos ocasionados devido ao mau uso dos recursos naturais (SILVA, 2007).

A implantação de plantios florestais com espécies de leguminosas arbóreas de rápido crescimento nas áreas impactadas é considerada uma alternativa viável para a reabilitação das mesmas (VEIGA; CARVALHO; BRASIL, 2000). O favão
(Parkia multijuga Beth) faz parte da família das leguminosas e é comum sua ocorrência na região Amazônica, em floresta de terra firme e várzeas altas em solos argilosos. Possui uma alta taxa de germinação homogênea, sua floração ocorre geralmente durante os meses de agosto e outubro e a maturação dos frutos no período de novembro a dezembro (LORENZI, 2008). Uma germinação mais rápida e homogênea é vantajosa para qualquer produção de mudas em viveiros, pois facilita um melhor controle das atividades subseqüentes até ao destino final da muda (OLIVEIRA; DAVID-CARVALHO, 2003).

O objetivo deste trabalho foi verificar o melhor método de quebra de dormência para o favão avaliando a taxa de germinação.

O estudo foi conduzido na Universidade Federal do Pará, Campus de Marabá em casa de vegetação da Faculdade de Ciências Agrárias de Marabá. As sementes da leguminosa arbórea usadas no experimento são procedentes do banco de germoplasma da Eletronorte de Tucuruí e foram semeadas em fevereiro de 2011 em sacos de polietileno de capacidade de $1 \mathrm{~kg}$ de solo.

Os tratamentos para quebra de dormência foram: testemunha (sem quebra de dormência) (TR1), escarificação mecânica (TR2) e imersão das sementes em $\mathrm{H}_{2} \mathrm{SO}_{4}$, por 16 minutos segundo Bianchetti, Teixeira e Martins (1998). O solo utilizado no experimento é proveniente da área a ser reabilitada onde há extração de argila, este 
caracteriza-se por ser um Latossolo Vermelho Amarelado, pouco fértil, considerado extremamente argiloso e ácido. Foram regadas diariamente conforme a necessidade da capacidade de campo e assistidas durante 90 dias.

O delineamento experimental em casa de vegetação foi um fatorial inteiramente casualizado (DIC), contendo uma espécie vegetal, um tipo de substrato, três métodos de quebra de dormência e 40 repetições, totalizando 120 vasos. Para obter o valor da germinação foi aplicado regra de três simples. Os dados foram analisados a partir de análise de variância e para a comparação entre as médias utilizou-se o Tukey a $5 \%$ de probabilidade, segundo metodologia descrita no software SISVAR (FERREIRA, 2000).

O melhor tratamento foi $\mathrm{o}$ de escarificação (TR2) (Tabela 1), que promoveu $100 \%$ de germinação do favão. As leguminosas possuem dormência tegumentar, onde muitos estudos têm investigado meios de escarificação, para otimização da germinação de determinadas espécies (SILVA et al., 2000 citado por PEREIRA; FERREIRA, 2010). A escarificação é um processo viável e eficaz, porém, devem-se tomar cuidados para não exceder o limite de escarificação do tegumento para não causar danos e atrapalhar a germinação (SANTOS; MORAIS; MATOS, 2004).

Tabela 1. Germinação do Favão aos 60 dias após a semeadura.

\begin{tabular}{lcc}
\hline Tratamentos & Plantas Germinadas & $\mathrm{N}^{\mathrm{o}}$ de plantas germinadas $(\%)$ \\
\hline TR1 & 0 & $0 \%$ \\
TR2 & 40 & $33,33 \%$ \\
TR3 & 4 & $3,33 \%$ \\
\hline
\end{tabular}

$\mathrm{Na}$ testemunha (TR1) não houve germinação aos 60 dias após a semeadura. A impermeabilidade do tegumento é a principal causa da dormência das sementes, podendo estar associada à presença de células em paliçada e uma camada de cutícula que protege o embrião, onde o cultivo de espécies em viveiros florestais que apresentam sementes dormentes torna-se um problema devido ao tempo demorado de germinação já que aumenta o período de desenvolvimento das mudas e facilita a suscetibilidade a ataques de pragas e doenças ocasionando perdas na produção e no econômico (SANTOS; MORAIS; MATOS., 2004). As espécies de leguminosas arbóreas 
caracterizam-se por possui interferência na absorção de água nas suas sementes, pois estas apresentam um tecido osteoscleides que impede a entrada de água e causa dormência por longos períodos atrasando a germinação (FOWLER BIANCHETTI, 2000).

A imersão da semente do favão em ácido sulfúrico por 16 minutos (TR3), promoveu uma baixa germinação, discordando com Biachetti (1998) que afirma que esse período e suficiente para superar a dormência do Favão (Tabela 1).

O método de superação da dormência do favão mais eficiente foi a escarificação mecânica.

\section{REFERÊNCIAS}

BIANCHETTI, A; T.; TEXEIRA, C. A. D.; MARTINS, E. P. Escarificação Àcida para superar a dormência de sementes de pinhocuiabano (Parkia multijuga Benth). Revista Brasileira de Sementes. v.20, n. 1,p.215-218, 1998.

FURTADO, F. D. Software Aplicativo para microcomputadores. Análise Multivariáveis. Departamento de Ciências Exatas. Universidade Federal de Lavras - UFLA-208 p. 2000.

FOWLER, A. J. P.; BIANCHETTI, A. Dormência em sementes florestais. Colombo: Embrapa Florestas, 2000. P.27 (Embrapa Florestas. Documentos, 40).
LORENZZI, H. Árvores brasileiras: Manual de identificação e cultivo de plantas arbóreas do Brasil, 5. ed. Nova Odima: Instituto plantarum de Estudos da Flora LTDA,2008. 171 p.

OLIVEIRA, L.M., DAVIDE, A. C., CARVALHO, M. L. M. Avaliação de métodos para quebra de dormência e para desinfestação de sementes de canafístula (Peltophorum dubium (Sprengel)) Taubert. Revista Árvore, Viçosa, v. 27, n. 5, p. 597603, 2003.

PEREIRA, S. A; FERREIRA, S. A. N. Superação da dormência em sementes de visgueiro-do-igapó (Parkia discolor). Acta Amazonica, Manaus, v. 40, p.151-156, 2010.

SANCHEZ, L. E. Desengenharia, o Passivo Ambiental na Desativação de Empreendimentos Industriais. São Paulo: Edusp, 2003. p 45-63.

SANTOS, T. O.; MORAIS, T. G. O.; MATOS, V. P. Escarificação mecânica em sementes de Chichá (Sterculia Foetida L.). Revista Árvore, Viçosa, vol. 28, n. 1, p. 1-6, 2004.

SILVA, J. C. S. Desenvolvimento inicial de espécies lenhosas nativas e de uso múltiplo na recuperação de áreas degradadas de cerrado sentido restrito - DF. $120 \mathrm{f}$. Dissertação - Universidade de Brasília, Faculdade de Tecnologia, Departamento de Engenharia Florestal, 2007. 
VEIGA, R. A. A.; CARVAlHO, C. M.; equações de volume para árvores de Acacia BRASIL, M. A. M. Determinação de mangium. Cerne, v. 6, n. 1, p.103-107, 2000. 